\title{
The Improvement of Discrete Wavelet Transform
}

\author{
Zhihua Zhang ${ }^{1}$ \\ ${ }^{1}$ Shandong University
}

August 1, 2021

\begin{abstract}
Discrete wavelet transform and discrete periodic wavelet transform have been widely used in image compression and data approximation. Due to discontinuity on the boundary of original data, the decay rate of the obtained wavelet coefficients is slow. In this study, we use the combination of polynomial interpolation and one-dimensional/two-dimensional discrete periodic wavelet transforms to mitigate boundary effects. The decay rate of the obtained wavelet coefficients in our improved algorithm is faster than that of traditional two-dimensional discrete wavelet transform. Moreover, our improved algorithm can be extended naturally to the higher-dimensional case.
\end{abstract}

\section{Hosted file}

polynomial-DWT.pdf available at https://authorea.com/users/428582/articles/532413-theimprovement-of-discrete-wavelet-transform

\section{Hosted file}

polynomial-DWT.tex available at https://authorea.com/users/428582/articles/532413-theimprovement-of-discrete-wavelet-transform 